\title{
\&UNG
}

\section{PERSPECTIVAS E AÇÕES DE DIFERENTES ATORES SOCIAIS NA GESTÃO E SUSTENTABILIDADE DO TURISMO EM PEDRA BELA, SP}

\section{PERSPECTIVES AND ACTIONS OF DIFFERENT SOCIAL ACTORS IN THE MANAGEMENT AND SUSTAINABILITY OF TOURISM IN PEDRA BELA, SP}

\author{
Jessica Alves Belgamo¹, Fabrício Bau Dalmas²
}

\section{RESUMO}

O presente trabalho compreendeu desenvolver estudos relacionados ao turismo sustentável e ecológico, contribuindo para subsídios de fomentos de atrativos turísticos visando o aumento progressivo de turistas. Através do planejamento turístico eficaz que contribuirá para o desenvolvimento e na infraestrutura do município de Pedra Bela, interior de (SP). A metodologia abordada fornecerá um levantamento bibliográfico e local da região, que apresentará uma coleta de dados para a determinação de fatores e perspectivas da gestão pública em ações sustentáveis e nos processos de uma reestruturação turística, com o intuito de aumento do fluxo de turistas e melhor qualidade de vida local. Neste estudo o objeto a ser apresentado é uma proposta de ações que auxiliem no processo de um planejamento sustentável e ecológico em Pedra Bela, fornecendo propostas para fomentar o crescimento turístico consciente para a minimização de impactos ambientais causados por atividades humanas e assim contribuir para o crescimento econômico. Os resultados obtidos desta pesquisa é apresentar ações e ferramentas para que os gestores públicos de Pedra Bela possam utilizar e aplicar de forma planejada e concluindo que as preservações destes recursos naturais são fundamentais tanto para a região como para o turista que irá utilizá-la de forma consciente.

PALAVRAS-CHAVE: Sustentabilidade. Planejamento Urbano. Pedra Bela. Turismo Ecológico e Religioso. Reestruturação.

\begin{abstract}
The present work includes the development of studies related to sustainable and ecological tourism, contributing to subsidies for the promotion of tourist attractions aimed at the progressive increase of tourists. Through effective tourism planning that will contribute to the development and infrastructure of the municipality of Pedra Bela, interior of $(S P)$. The methodology will provide a bibliographical and local survey of the region, which will present a data collection for the determination of factors and perspectives of public management in sustainable actions and in the processes of a tourism restructuring, with the purpose of increasing the flow of tourists and better quality of life. In this study, the object to be presented is a proposal for actions that will assist in the process of a sustainable and ecological planning in Pedra Bela, providing proposals to promote conscious tourism growth for the minimization of environmental impacts caused by human activities and thus contribute to growth economic. The results obtained from this research are to present actions and tools so that the public managers of Pedra Bela can use and apply in a planned way and concluding that the preservation of these natural resources are fundamental for both the region and the tourist that will use it in a way conscious.
\end{abstract}

KEYWORDS: Sustainability. Urban Planning. Stone. Ecological and Religious Tourism. Restructuring.

\footnotetext{
1 Universidade UNG. Discente no Curso de Bacharelado em Turismo. Rua Engenheiro Prestes Maia, n 88 - Centro, Guarulhos - SP, 07023-070. E-mail: j_belgamo@hotmail.com.

2 Universidade UNG. Programa de Mestrado em Análise Geoambiental, Praça Tereza Cristina, 239, 07023-070, Guarulhos, SP, Brasil. E-mail: fdalmas@prof.ung.br.
} 


\section{INTRODUÇÃO}

Segundo a OMT (2017), definir o conceito de turismo seria entender que o "Ato de viajar se aplica no deslocamento do turista para outra cidade com intuito de fugir da sua rotina diária, por um período inferior a um ano, e com propósito principal, de lazer ou entretenimento, o que não inclui uma atividade remunerada".

O papel fundamental do turismo como uma atividade econômica sustentável é proporcionar a inclusão social sem que possa gerar grandes impactos para as áreas ambientais, gerando qualidade do ambiente apresentando uma preservação do espaço e por consequência um desenvolvimento econômico de Pedra Bela.

O Ministério do Turismo inova na condução de políticas públicas com um modelo de gestão descentralizado, orientado pelo pensamento estratégico.

O processo de gentrificação compreende avaliar a reestruturação do espaço urbano ou rural, preservando características naturais e modificando o crescimento desordenado da população local, impedindo um maior aumento de impactos causados por turistas em massa (SMITH, 2007).

Segundo o Ministério do Turismo (2003), podese compreender por turismo sustentável a responsabilidade de preservação dos recursos naturais, culturais (religiosos) e históricos, assim permitindo que os turistas usufruam destes atrativos, com o menor impacto ao meio ambiente e a sociedade. Esses tipos de turismo investem nos atrativos e equipamentos turísticos, que fornecem renda local e desenvolvimento socioeconômico através do fortalecimento desse tipo de turismo (BOSETTI \& OLVEIRA, 2016).

O planejamento e a gestão do turismo vêm apresentando-se como uma grande preocupação para todos os profissionais interessados na sustentabilidade da atividade. Tal preocupação se fundamenta nos inúmeros exemplos de impactos socioambientais, econômicos e culturais negativos existentes em todo o mundo, decorrentes do crescimento desordenado da atividade turística (SEABRA, 2001).

$A$ área em estudo, localizada no município de Pedra Bela, SP, que apresenta a quantidade de aproximadamente 6.000 habitantes, consideravelmente uma população pequena, porém, com um potencial de desenvolvimento turístico característico para quem busca um Turismo religioso e de ecoturismo, decorrente de atrativos como a Pedra Santa e dentre outras com histórias religiosas, acoplado com a maior tirolesa da América do sul, trazendo muita aventura, contudo, a economia do município gira em torno desses atrativos, festas típicas e religiosas que oferecem ao turista um pouco da história e acolhimento que Pedra Bela/SP por proporcionar (http:// www.pedrabela.sp.gov.br/).

Dias (2003) os conjuntos de ações executadas pelo Estado permitem a atender às necessidades de toda a sociedade. As políticas públicas são direcionadas como ações e diretrizes que visam beneficiar a sociedade, trazendo melhorias e soluções compatíveis de interesse público. Contudo, segundo Rua (2006) existem dois grandes desafios de toda política pública são a construção de decisões que agreguem consenso entre os diferentes atores sociais e assegurar que as decisões tomadas serão implantadas.

Este trabalho consiste em uma análise de fatores que possam contribuir para o município de Pedra Bela, interior de São Paulo, tenha um desenvolvimento turístico sustentável, aplicando perspectivas e ações que possam contribuir para um aumento de turistas que buscam esses atrativos e por consequência gerar fomentos para o crescimento exponencial de Pedra Bela, através um planejamento eficaz que gerencie e reduza ao máximo os impactos turísticos das áreas preservadas e de uso coletivo.

\section{OBJETIVO}

\subsection{Objetivo geral}

Apresentar subsídios e ações de um planejamento turístico-sustentável através do processo de gentrificação em Pedra Bela, SP.

\subsection{Objetivo especifico}

Oferecer um instrumento de desenvolvimento turístico para o crescimento ordenado e planejado, promovendo opções de atrativos e uso dos recursos naturais de forma adequada que contribua para a preservação total ou mínima das reservas.

\section{JUSTIFICATIVA}

O município de Pedra Bela, SP apresenta muitos recursos naturais, a base econômica do município é constituída da agropecuária, destacando-se atualmente o cultivo de eucaliptos e a produção de carvão vegetal, contudo, fornece recursos naturais e atrativos que contribuem para o fluxo de turistas interessados em um turismo religioso e de ecoturismo, daí surge a importância de desenvolver ações estratégicas que enfatiza a necessidade de estudos que 
contribuam para a elaboração de políticas públicas que possam embasar planos turísticos sustentáveis aliados à conservação dos recursos naturais.

Através da reestruturação causada pelo aumento de impactos e transformações socioambientais locais, é importante desenvolver estes planejamentos para que o município se desenvolva ordenadamente e apresente infraestrutura necessária para acolher os turistas e manter qualidade de vida local.

\section{FUNDAMENTAÇÃO TEÓRICA}

\subsection{Localização da Área em estudo}

A área de estudo deste projeto é o Município de Pedra Bela, encontra-se situado no interior do Estado de São Paulo, precisamente na região administrativa de Campinas e na região do governo de Bragança Paulista, a 112 km da capital paulista. O município possui uma população de 6.000 habitantes, o que caracteriza um município com potencial em desenvolvimento, observado na (Figura 1) (http:// www.pedrabela.sp.gov.br/).

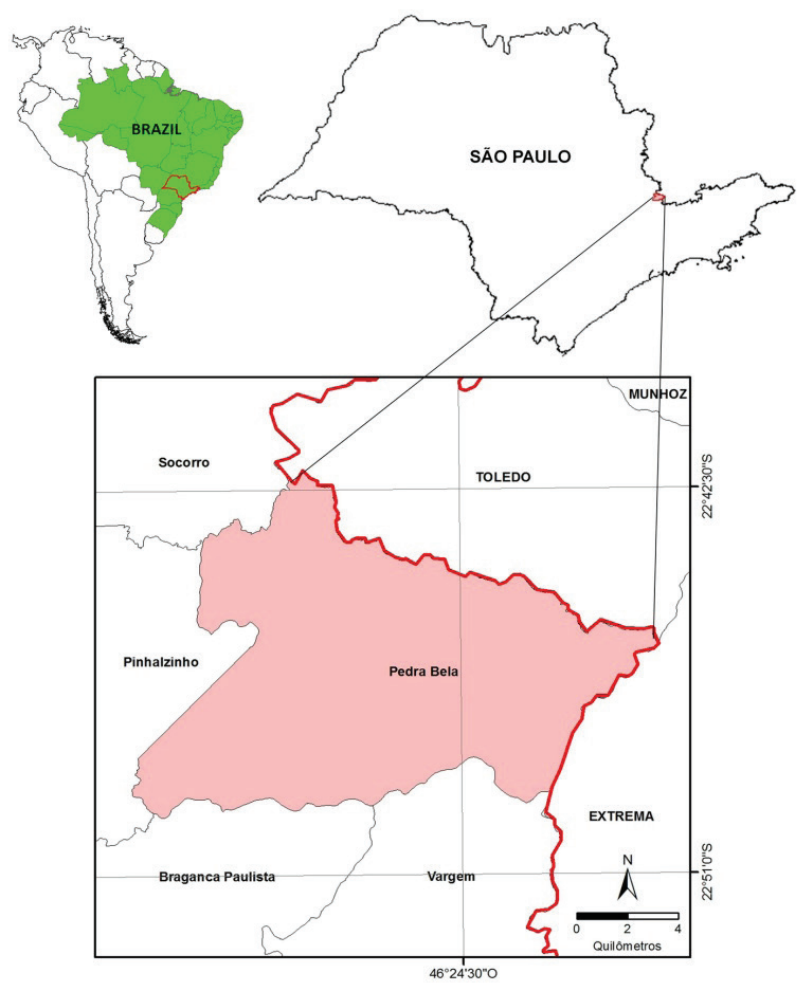

Figura 1. Localização do Município de Pedra Bela. (Fonte: elaboração própria).

Location of the Municipality of Pedra Bela. (Source: own elaboration).

Pedra Bela está numa altitude média de 1.100 $\mathrm{m}$ em relação ao nível do mar e está localizada na
Serra da Mantiqueira, na Área de Proteção Ambiental do Piracicaba/ Juqueri /Mirim. Possuem belíssimas cachoeiras, montanhas, trilhas e é muito valorizada por obter Recursos naturais diversificado, conta ainda com a maior tirolesa das Américas, atraindo os turistas que buscam por ecoturismo, religiosidade, um povo com influência mineira sendo o predominante do município(http://www.pedrabela.sp.gov.br/).

O desenvolvimento econômico do município é baseado na agropecuária, destacando-se atualmente o cultivo de eucaliptos e a produção de carvão vegetal. Outros destaques são a suinocultura e os micros estabelecimentos industriais que beneficiam milho em produtos como fubá, farinha e canjica, de grande conceito e aceitação em toda a região. E claro, o fluxo turístico é um grande fator para a renda da cidade (http://www.pedrabela.sp.gov.br/).

\subsection{Histórico da área}

Conhecido por ser um município religioso, $\mathrm{Pe}$ dra Bela, antigamente denominada Santa Cruz do Feital foi fundada por José Antônio de Oliveira, no ano de 1869, integrando o apogeu paulista do ciclo do café. Em 1929 o povoado tornou-se Distrito de Bragança Paulista e em 1930 foi elevado à categoria de Vila. Em 1945 o nome da Vila da Pedra Grande, foi alterado para Pedra Bela. A emancipação político-administrativa deu-se em janeiro de 1964, sendo José Bueno de Miranda o primeiro prefeito do Município(http://www.pedrabela.sp.gov.br/).

\subsection{O Turismo em Pedra Bela - Atividades Turís- ticas versus Impacto Ambiental}

O crescimento urbano de Pedra Bela, afeta de maneira geometricamente crescente as condições ambientais do município, e a qualidade de vida da população, ao longo do tempo poderá ser comprometida pela falta de planejamento e de reestruturação (Gentrificação), pois mesmo que, quando comparada à situação de outras cidades médias brasileiras, Pedra Bela não esteja em situação alarmante, é preciso ter consciência dos fatos, antes que eles assumam dimensões incontroláveis. As atividades turísticas geram grandes impactos, e é preciso discussão, elaboração e implementação de projetos socioambientais responsáveis, embasados em princípios da preservação do meio ambiente, em acordo com a legislação vigente, e principalmente sem transgressões às leis naturais (GAMEIRO; SUGUIO, 2008)

O município de Pedra Bela é completo por seus 
recursos naturais, possui uma linda paisagem, repleta de cachoeiras, montanhas, trilhas e rochas que apresentam histórias religiosas que fornece grande turismo, o clima agradável de interior, próximo a Bragança Paulista e Socorro, duas Estâncias Turísticas e está integrada ao Circuito Entre Serras e Águas, determinadas pela Secretaria de Turismo do Estado de São Paulo.

Esses circuitos reúnem cidades com grande potencial turístico que estão organizados em segmentos de interesse do turista ou temas como: religioso, ecológico, histórico-cultural, tecnológico e gastronômico com a proposta de gerar fluxo turístico(http:// www.pedrabela.sp.gov.br/).

Os principais pontos turísticos do município localizado em uma rocha é o Santuário de Nossa Senhora Aparecida, onde podemos ter a visão de toda acidade (Figura 2), ainda acoplado a esta rocha tem o início da maior tirolesa da América que finaliza no portal da cidade com a extensão de 1.900 metros.

Esses atrativos desenvolvem todo o turismo da cidade, recebendo milhares de pessoas todo ano, que buscam esse tipo de turismo, a cidade conta com as comemorações do dia 12 de outubro anualmente que contribui para aumento de turistas (http:// www.pedrabela.sp.gov.br/).

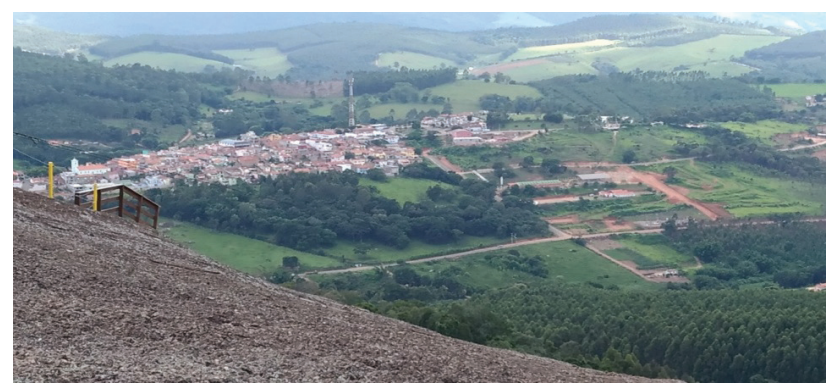

Figura 2. Vista de cima da Pedra do Santuário do município de Pedra Bela, SP. Fonte: arquivo pessoal - Dezembro/2017.

Top view of the Shrine Stone of the municipality of Pedra Bela, SP. Source: personal archive - December / 2017.

\subsection{Atributo Físico: Atrativos Turísticos Naturais}

Pedra Bela apresenta um conjunto de atrativos naturais de interesse de muitos turistas, apresentando além destes atrativos como a tirolesa, inserida nestes recursos naturais o que configura a paisagem física da cidade, através de montanhas, cachoeiras, trilhas e grandes relevos que compõem esse produto turístico. Esta oferta turística oferece tanto ao turista quanto aos seus habitantes uma qualidade de vida impagável, o contato de forma menos impactante possível (http://www.pedrabela.sp.gov.br/).

É importante atentar-se as intervenções e os impactos causados pelo homem, a busca por exploração de ambientes preservados é motivada pelo desejo de interagir com um ambiente totalmente diferente do seu cotidiano, buscando conforto e novas experiências, o que contribui para o aumento de recursos para fornecer esses atrativos turísticos naturais de forma organizada e planejada (BARRETO, 2008).

\subsubsection{Paisagem}

Segundo Palma (2010), o município de Pedra Bela é valorizado por seus recursos naturais como as rochas e suas histórias, suas paisagens são compostas por diferentes unidades de relevo onde predominam as Serras, os Morros Altos e os Vales Fluviais. A variação de declividade, cerca de $5 \%$ a $30 \%$ favorece a contemplação deste relevo peculiar e de rara beleza que remete as paisagens europeias, o que é bem característico de PB, transformando em lugar admirável de ser contemplativo.

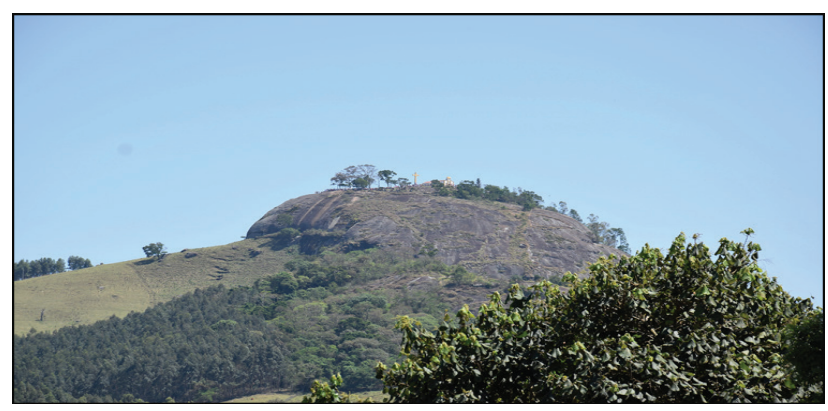

Figura 3. Paisagem com vista a Pedra Grande ou Pedra do Santuário. Fonte: arquivo pessoal - outubro 2017. Landscape with view of the Great Stone or Shrine Stone. Source: personal archive - October 2017.

\subsubsection{Cachoeiras}

Considerada um recurso natural capaz de transformar destinos em forte núcleo turístico, as cachoeiras de Pedra Bela compõem a infraestrutura turística da cidade que se utilizam da hidrografia do município. A conhecida Cachoeira da Boca da Mata localizada no Ribeirão das Araras a aproximadamente $20 \mathrm{~km}$ da região central, considerando o precário acesso e estado de conservação da cachoeira, pode ser avaliada como regular (Figura 4). As atividades de aventura ou ecoturismo em Pedra Bela, ainda não se encontram em total desenvolvimento e aproveitamento dos recursos naturais, em benefício do município, porém, é sabido que os moradores e amantes 
da natureza do local se mobilizam realizar passeios pelas trilhas e cachoeiras distribuídas em todo município de maneira preservada e sustentável.

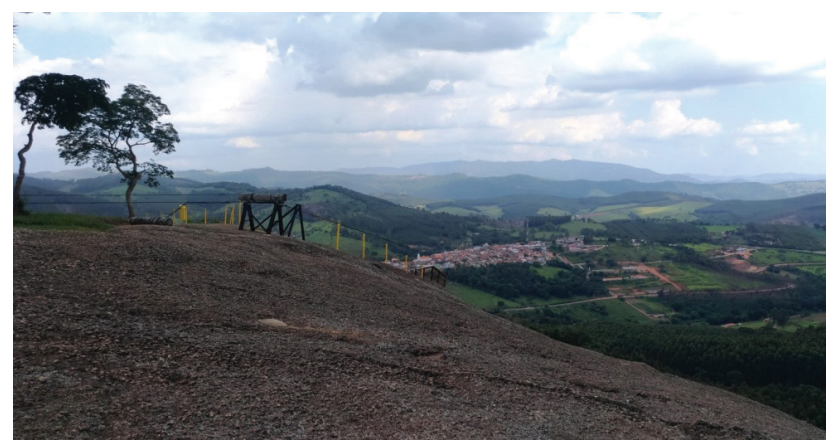

Figura 4. Tirolesa de $2 \mathrm{~km}$ de distância. Fonte: arquivo pessoal - dezembro de 2017.

Zipline $2 \mathrm{~km}$ away. Source: personal archive - December 2017

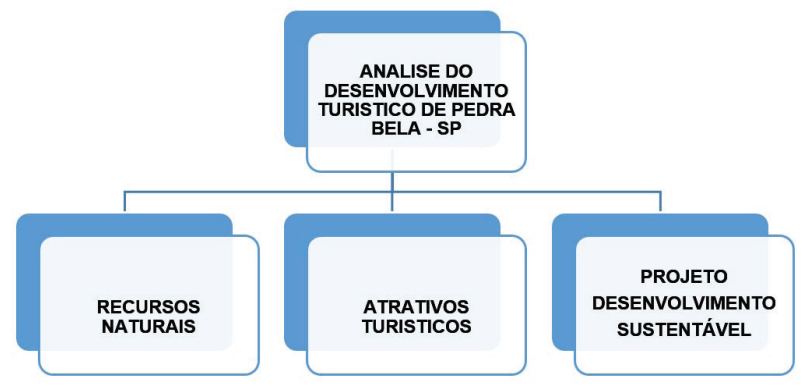

Figura 5: Esquematização dos principais tópicos aplicados para a elaboração desta pesquisa.

Outline of the main topics applied for the elaboration of this research.

\subsubsection{Trilhas}

Pedra Bela conta com que incluem diferentes maneiras de operação como a pé, a cavalo, jipes e bicicletas para contemplação da paisagem, conteúdo, é percebido também a ausência de informações e sinalização nas trilhas e estradas rurais, o que dificulta a autonomia do visitante, que irá depender de um guia local para acompanhá-lo, o que fomenta e impacta a economia do setor, e a prática de trilhas de maneira responsável e sustentável.

\subsubsection{Montanhismo}

Em Pedra Bela a modalidade de escalada é favorecida pela configuração do relevo, vias curtas de acesso e com boa ancoragem, porém, inexiste uma regulamentação ou fiscalização da modalidade no município, o que deve ser motivo de preocupação com vistas ao impacto ambiental.
O aumento das vias de escalada e o rapel são modalidades esportivas que requerem bastante monitoramento e fiscalização, sempre com auxílio de um guia/monitor promovendo a redução de impactos, uma vez que os percursos utilizados pelos escaladores são sempre os mesmos, entretanto, é necessário estar atento aos que se aventuram em criar novas vias de escalada, o que provocará o impacto ambiental, repelindo os animais sensíveis a presença humana, destruição da flora que existam nas fissuras das rochas e a compactação do caminho ao redor da parede, tornando necessário um controle e planejamento ambiental para esse tipo de prática.

\subsubsection{Tirolesa}

A Tirolesa conhecida como a maior da América com $1.900 \mathrm{~m}$ de distância o que atrai muitos turistas de todos os lugares, traz uma atividade para quem busca turismo esportivo com descida em cabo fixo, de deslocamento rápido onde o deslize acontece com o auxílio obrigatório de roldanas, mosquetões e uma cadeirinha de alpinismo, ligando dois pontos distantes e que permite a sensação de sobrevoar, geralmente em meio a natureza, sem esforço por parte do praticante (Figura 4).

Para a realização do esporte de aventura, se torna fundamentais treinamentos experienciais ligados ao desenvolvimento de atividades que representem algum tipo de risco aos seus praticantes, devem ser acompanhados por profissionais capacitados. As entidades que estão autorizadas pelo Instituto Nacional de Metrologia, Qualidade e Tecnologia (Inmetro) a fazer a certificação são: ABNT Certificadora e Instituto Falcão Bauer da Qualidade.

\subsection{Turismo e Sustentabilidade}

Para Ruschmann (1999) as atividades antrópicas constantes em áreas preservadas implicam diretamente em pequenos impactos que podem degradar o meio ou até destruí-lo. Esses danos podem ser muitas vezes irreversíveis e afeta a qualidade de vida local, a saturação de turistas em hotéis que aumenta a produção de lixo e que muitas vezes não existe tratamento e até o aparecimento de depósitos de lixos ilegais, além de poluição sonora e visual, com edifícios e prédio que não integram a paisagem, são casos que precisam ser avaliados, pois não tem controle sobre essas áreas abertas.

Para Swarbrooke, (2000) as atividades turísticas devem estar integradas a um plano de desenvol- 
vimento sustentável, pautadas em ações que permitam benefícios para o bem-estar da população local, sem impactos negativos para o meio ambiente e com garantia de melhores dias para as gerações futuras. Deve estar incorporado a ações que tolerem crescer de maneira responsável e o conceito sustentabilidade deve estar pautado sobre três fatores: qualidade - continuidade e equilíbrio.

\subsection{Impactos do Turismo}

O ecoturismo é nada mais que necessidade do turista em conhecer ecossistemas e culturas diferentes da sua, possibilitando a relação do homem com a natureza de forma passiva e sustentável. De acordo com Swarbrooke (2000), o ecoturismo é traduzido a necessidade de explorar o desconhecido e apreciação de ver ecossistemas em seu estado natural.

Para Ruchsmann (2003), o turismo é uma atividade que depende de pessoas para acontecer, são sucedidas por deslocamentos, ou seja, movimentação de pessoas para todos os lados do planeta, e com isso, provoca impactos sociais, econômicos e ambientais, e podem ser positivos e ou negativos.

\subsection{Planejamento Turístico}

Para Ruschmann, (1999), planejar é um processo que se caracteriza por determinar um cenário futuro positivo e desejável, que são possíveis a partir da criação e definição de políticas e processos de implementação e ações com prazos pré-estipulados.

Para um planejamento turístico, deve-se pensar em maximizar os benefícios socioeconômicos e minimizar os impactos socioambientais advindos das atividades promovidas pelo turismo, uma vez que o crescimento desordenado precisa ser controlado e planejado para promover o desenvolvimento turístico sustentável (ABRAMOVAY, 2010).

Segundo Ruschmann (1999), para que seja possível alcançar o nível de qualidade da atividade turística, é necessário colocar em prática alguns dos princípios básicos do planejamento turístico, o que se espera para um município com vocação turística e que seja receptora, é que consiga através da ferramenta do planejamento turístico, destacar-se como uma cidade economicamente viável, socialmente justa e ecologicamente correta.

\section{METODOLOGIA}

Os procedimentos metodológicos aplicados para esta pesquisa utilizarão critérios de envolvimento dos principais atores sociais (comunidade, gestores públicos e profissionais capacitados) visando à elaboração de um plano fundamentado por um levantamento de todos os recursos naturais, atrativos turísticos, estrutura administrativa da gestão do município de Pedra Bela e o perfil da população local e dos turistas, através de dados obtidos pela prefeitura.

Considerando que esta pesquisa terá como objetivo identificar perspectivas e ações de diferentes atores sociais na gestão e sustentabilidade do turismo no município de Pedra Bela metodológicos em três fases, sendo a exploratória, o trabalho de campo e análise dos dados obtidos.

Com base nos dados que serão obtidos através desta pesquisa, um trabalho de campo, revisão literária e conceitos de perspectivas e as ações sustentáveis necessárias, serão fundamentais para o desenvolvimento da elaboração do plano contendo as propostas de inserção de fatores executáveis que contribuirão para o controle e suporte turístico do município.

\section{RESULTADOS}

O município de Pedra Bela-SP, é composto por muitos recursos naturais, a paisagem natural, o clima tropical, as diversidades de fauna e flora inexplorada, cachoeiras e riachos, formações rochosas que fazem jus ao seu nome (PALMA,2012).

A elaboração de uma análise do desenvolvimento turístico no município de Pedra Bela, requer os levantamentos bibliográficos de seus principais recursos naturais e seus atrativos turísticos, aplicando ações e subsídios que fomentem o turismo na região.

Do ponto de vista profissional, a viabilização de estratégias para incremento de potencializar o turismo em Pedra Bela requer estudos e levantamentos de dados do fluxo turístico e quantificar os perfis dos visitantes e desenvolver técnicas inovadoras que trabalhem para o turismo tanto religioso quanto de aventura, uma metodologia aplicável a este projeto é adaptar o Ecoturismo, uma grande ferramenta de desenvolvimento Sustentável a ser praticada em Pedra Bela.

Conforme a Lei complementar $n^{\circ} 75 / 2006$ apresenta questões fundamentais para o Desenvolvimento de Pedra Bela em seu Título II, Capitulo I, Seção II, que a prefeitura deverá elaborar no Pdtur "Com vistas a promover o desenvolvimento do turismo no município de forma inteiramente sustentável, garantindo a manutenção e preservação dos recursos ambientais e proporcionando as devidas condições de uso e trabalho por todos". 
Há também uma relevância deste levantamento turístico contribuir como fonte de consulta para empresários com interesses econômicos na atividade turística a fim de promover novos empreendimentos e atrativos conforme a estruturação local.

Segundo Wearing e Neil (2001), o ecoturismo está intimamente interligado ao desenvolvimento sustentável, sendo uma prática que proporciona a minimização dos impactos ambientais provocados pela população e o turista. A conscientização e diminuição da exploração dos recursos florestais.

O projeto sobre o desenvolvimento sustentável em Pedra Bela será composto por elementos fundamentais como as noções de movimentação da área, na sua conservação sendo o mais natural possível, induzir o papel da educação ambiental através de roteiros explicativos e didáticos, as palestras e definição do tipo de turismo são de grande importância e priorizam a ideia de mitigar os impactos ao meio ambiente ao longo dos anos.

Sendo assim, para um planejamento turístico, deve-se pensar em maximizar os benefícios socioeconômicos e minimizar os impactos socioambientais advindos das atividades promovidas pelo turismo e os recursos naturais como fomento (PARRA, 2018).

\section{CONSIDERAÇÕES FINAIS}

O turismo é uma atividade relativamente nova, surgindo em meados do século 19, através da necessidade de alimentos e por territorialismo, com o passar dos anos e os avanços tecnológicos permitiram as transições de turistas no mundo todo, gerando atividades econômicas para os países.

Contudo, torna-se cada vez mais necessário desenvolver e promover as preservações desses atrativos e Recursos, visando a garantir a sustentabilidade da comunidade local.

Com base nas colocações acima mencionadas, este projeto apresentou ideia se uma análise do desenvolvimento turístico de Pedra Bela/SP, contribuindo para o plano diretor de turismo da região, afim de buscar alternativas que atribuam ao plano a trazer uma visão ampla das possíveis consequências das atividades turísticas na região, com um projeto de viabilização ecoturistica com ações que possam intervir em possíveis impactos ambientais no futuro.

Sendo assim, com vistas a promover o desenvolvimento do turismo no município de forma inteiramente sustentável, estabelece a proposta de organização e manutenção dos recursos ambientais, com um planejamento contínuo e com a participação dos atores sociais (Governos, população e profissionais qualificados) proporcionando as devidas condições de uso e trabalho por todos. 


\section{REFERÊNCIAS}

ABRAMOVAY, Ricard. Desenvolvimento sustentável: qual a estratégia para o Brasil? Novos estud. CEBRAP, São Paulo, n. 87, p. 97-113, jul.2010. Disponível em: <http://www.scielo.br/scielo. S010133002010000200006\&lng=pt\&nrm=iso $>$. Acesso em: 18 dez. 2017.

BARRETO, Margarita N. Angeli. Planejamento e Organização em turismo. 9.ed. São Paulo. Campinas: Papirus, 2003. (Coleção Turismo)

BOSETTI, S. C.; OLIVEIRA, P. V. Ecoturismo e o turismo rural como estratégia de desenvolvimento sustentável: um estudo em propriedades rurais da região da amauc/sc. Ágora: R. Divulg.Cient., v. 21, n. 1, p. 43-63, jan. /jun. 2016 (ISSNe 2237-9010).

DIAS, R. Turismo sustentável e meio ambiente. São Paulo: Atlas, 2003.

GAMEIRO, S. M.; SUGUIO, K. Problemas geoambientais provocados pela expansão urbana no município de Bragança Paulista, SP. Revista UnG - Geociências. v.7, n.1, 2008, 48-63.

Ministério do Turismo. Diretrizes para o desenvolvimento do turismo rural. Brasília, DF: Ministério do Turismo, 2003.

OMT (Organização Mundial do Turismo) - Introdução ao Turismo. Ed. Roca: 2001.
PALMA, Luana Cunha. Análise Geoambiental e Turismo: novas possibilidades turísticas para o município de Pedra Bela-SP. Dissertação de Mestrado em Análise Geoambiental. Guarulhos, 2012.

PARRA, R. C. Análise da capacidade de carga turística e determinação de visitação no planejamento e gestão do turismo na cidade de Pedra Bela SP. Dissertação de Mestrado em Análise Geoambiental. UNG. Guarulhos, 2018.

Pedra Bela. Disponível em: http://www.pedrabela.sp. gov.br. Acesso em: 02 dez. 2017.

RUSCHMANN, D. Turismo e planejamento sustentável: a proteção ao meio ambiente. Campinas, SP: PAPIRUS, 1999. (Coleção Turismo) 4.ed.

SEABRA, G.F. Ecos do turismo: o turismo ecológico em áreas protegidas. Campinas: Papirus, 2001, p. $74,220-221$.

SMITH, N. Gentrificação, a Fronteira e a Reestruturação do Espaço Urbano. GEOUSP - Espaço e Tempo, São Paulo, n.21, pp. 15-31, 2007.

SWARBROOKE, John. Turismo sustentável: conceitos e impacto ambiental. São Paulo: Aleph, 2000.

WEARING, S; NEIL, J. Ecoturismo: impactos, potencialidades e possibilidades. Barueri, SP: Manole, 2001. 